\title{
The Changing Roles of a Language Learning Center at a Residential Liberal Arts College in the Midst of Technological Development
}

\author{
Jing Wang \\ Director, Language Learning Center (LLC) \\ Allegheny College
}

The widespread availability of simplified technology and the increasing technical expertise of the average lab user confront directors of Language Learning Centers (LLC) with the question of the legitiMacy of the existence of their centers. This case study of the LLC at Allegheny College, a liberal arts institution for 2,100 students, demonstrates the crucial function of the LLC in the midst of technological development. Allegheny's explicit mission of educating well-rounded students who can learn, communicate, analyze and solve problems in a residential setting requires that the LLC assist with the implementation of diverse curricular goals and needs. The following article discusses how the LLC fulfills these roles, which are relevant to other institutions of higher learning as well.

A Relevant Context

Our LLC is housed in the department of Modern and Classical Languages at Allegheny College. The department offers regular language instruction in Spanish, French, German, Latin and Chinese; and also teaches American Sign Language, Arabic, Greek, Italian, and Intensive English through the department's Center for Language and Culture. Enrolling around four hundred students each semester, the department offers a variety of language-related majors and minors. 
After successfully obtaining a Mellon Grant and with additional money bequeathed to us by a former French professor, Blair Hanson, the department was able to renovate the old style audio lab into the present LLC in 1998. The Blair Hanson Center is a 2,100 square foot space occupying the third floor of Ruter Hall. It contains a central service desk and an adjoining lounge area; a glassed-in computer laboratory with 19 networked stations, a multimedia projector, and a control podium; a small group tutorial room; a courseware developer's room; cabinet storage space; and several offices. The center's website can be found at http://webpub.allegheny.edu/dept/language/index.html.

When the LLC was first set up, it was at the vanguard of technological advancement on our campus. Now, eight years later, Allegheny College has made great progress in the use of educational technology. Besides the LLC, there are eleven other public computer labs on campus (http://help.allegheny.edu/tutorials/labinfo.php). Seventy percent of our students also have their own personal computers. Since more and more computer technology is available even in the far reaches of the student dorms, what draws students to still make use of the LLC? In the midst of continuing technological development, what functions does the Blair Hanson LLC perform in facilitating language instruction and learning at Allegheny College?

In general, the Blair Hanson LLC is engaged in the following tasks: we provide a comfortable environment for language communication, offer technical support to students and faculty members, and add pedagogical perspectives for the use of technology in language instruction. We readily supply language learning resources and software, and, apart from offering instructional space, we conduct student assessments and promote overall language awareness on our campus.

\section{An Inviting Place for Interaction and Language Learning}

Our center encourages personal interaction to facilitate language learning. Personal interaction for language learning is crucial at Allegheny College because it not only promotes language acquisition but also aligns with the mission statement of the College. Gass (2003) summarized the literature in the field of second language acquisition and indicated that "interaction and learning are related" (244). The livelihood of the LLC rests on its agreement with the mission of Allegheny College: as is often the case in a residential liberal arts college environment, both faculty-student and student-student interaction to promote learning are highly valued. Compared to other places on campus, the Blair Hanson LLC is an ideal place to engage in personal interaction and communication. The ample 


\section{A Place for Technical and Pedagogical Support}

Support for Students space and the comfortable environment make face-to-face encounters possible, and language resources like foreign films and magazines provide ample fodder for communication. In the LLC lounge, student tutors and faculty members often show films to small groups of students and then lead discussions; in the tutorial room of the LLC, student tutors and faculty members often practice languages with students on an individual basis. Students also come in small groups to prepare oral assignments. Our environment makes it comfortable for students to interact asynchronously through computer technology. Without fear of speaking out in public, students can record their oral performances and transfer the sound files to audio drop boxes that faculty members can then access from their office computers. By staying open until $11 \mathrm{pm}$ during weekdays and for thirteen hours during the weekends, the LLC is an attractive place for students to come and study languages.

As the LLC director I work one third of my time in the LLC and spend the other two thirds of my time in language instruction. Every semester I hire about twelve to fifteen students, most of whom are language students, to work as lab assistants; and one or two additional students who work for me as technologists. Each LLC assistant works on average four to six hours per week. At the beginning of their assignments, LLC assistants receive some basic computer training and an orientation which familiarizes them with their lab managing duties: they have to monitor the performance of computers and printers, solve basic computer problems, check language resources and equipment in and out, and report computer problems to computing services. Our student technologists usually have more advanced computer skills than our LLC assistants. The LLC director, the student technologists, and the LLC assistants work as a team to offer both technical and pedagogical support to faculty and students.

Students may encounter a variety of problems when using computers for foreign language assignments: international keyboards, font choices, input and output systems of non-western characters, and foreign spelling checkers can put up a variety of obstacles. Students normally do not have the expertise to configure their own computers in order to handle foreign language tasks, and the other computer labs that are available on campus are merely set up for general purposes. Since the computers in the Blair Hanson Center have been specifically prepared to accommodate the needs of learners of different foreign languages, students rely on our equipment to do their language homework and to access foreign language courseware. Besides working on their written assignments, students also seek help in completing other assignments such as listening to audio files and viewing video clips from the LLC computers that are connected 
to a server at the LLC. They can record and convert their oral assignments into MP3 files and then upload them to the aforementioned drop boxes. The LLC provides all necessary equipment such as headsets, speakers, and microphones, and our assistants offer support to students to help them complete and digitize their assignments.

Technical Support for Faculty Members
The LLC also provides support to faculty members. Technical support is divided into two areas: technical support in using different equipment and software to facilitate language instruction, and technical support in designing interactive language materials and in doing research. Technical support of the first kind covers a wide range of areas: solving computer problems, setting up audio-visual (AV) equipment, updating homepages to list the newest information on course offerings, extracting files from $\mathrm{CDs}$ and putting the files on the server, making video clips, recording news programs from satellite TV programs, converting foreign videotapes into playable formats, setting up audio drop boxes, mapping office computers to our server, and providing assistance with the various software packages that are being used for language instruction.

However, we also provide support when it comes to developing course materials and doing language-related research. Sometimes faculty members like to design their own interactive language materials in order to seamlessly incorporate them into their particular curriculum. When this is the case, the LLC offers technical support with video production, sound file subtraction, and a variety of other tasks. In fact, this kind of technical support is not limited to faculty members in the department of Modern and Classical Languages. Faculty from other departments and staff from the library also have begun to request technical support in converting foreign-made AV materials into formats which can be played back on standard AV equipment. Since the LLC is located in the language department, however, the needs of our departmental faculty members are met more immediately. 
Pedagogical Support for Faculty Members
The LLC also provides pedagogical support in using new technologies for the teaching of languages. As it was already pointed out by Garrett (1997), "perhaps the most far-reaching change in our relationship [as LLC directors] with the faculty is likely to come as a result of the increasing fusion of technology and pedagogy" (29). In my role as a pedagogical supporter for language faculty members at Allegheny, I, as the LLC director, not only demonstrate how to use software, but also try to explore and solidify its pedagogical applications. For example, I have investigated with faculty members how to use WebCT as a communication forum to facilitate the teaching of different skills. To improve their listening and speaking skills, students can gain access to audio files via the WebCT interface, which they can also use to submit recordings of their own oral assignments. They can use Audacity, a free software program, to record their oral exercises and then save their recordings as $\mathrm{mp} 3$ files. There are several options for submitting their recordings to WebCT. They can attach them to messages and submit them to the discussion area, send them as WebCT email, or post them in the student presentation area. Based on his or her pedagogical objectives, the instructor chooses the most appropriate place on the WebCT site for students to submit their recordings. If the instructor wants to start an asynchronous discussion, he or she can ask students to submit their recordings to the student discussion area. Students can then listen to the recordings of other class members, and respond by submitting their follow-up recordings to the discussion area. This kind of discussion is different from the classroom discussion. It is more decentralized since neither the instructor nor one or two articulate students are able to dominate the discussion forum. Everyone is given an equal chance to present his or her ideas. In addition, students have an opportunity to give thoughtful responses rather than spontaneous answers, since they can record themselves several times and only submit their best recordings to the forum.

WebCT, like other content management systems (e.g. Blackboard, Moodle), can also be used to facilitate the teaching of writing. In conventional text writing, it is difficult to convince students that they are writing to convey meaning. Too often students view writing assignments just as busy work that needs to be done to please an audience of one-their instructor. It does make a difference whether students post their writings on WebCT and then are asked to critique that of their peers. Online critiquing provides a sense of communication for real purposes for both writers and readers. Students who post their writing realize that they are communicating with an audience and their writing needs to make sense. Students who do the critiques try to understand the meaning of the posted passages, and then comment on the ideas, structures, grammar, and spelling 


\section{A Center of Many}

Resources

\section{A Place for \\ Demonstration and Language Assessment}

of their classmates. Furthermore, by critiquing each other's writings, students themselves develop a sense of "reader consciousness". Writing and reading now become communication instead of mere drudgery. Incorporating technology into the teaching process can thus facilitate the teaching of writing.

Allegheny's LLC provides a plethora of resources for language learning, and our students rely on it to access a rich variety of language learning materials far beyond what they could acquire on their own. The LLC has international magazines, foreign videotapes in all three formats (NTSC, PAL and SECAM), DVDs of different regions, audio tapes, digitized audio and visual materials, interactive language learning software, and SCOLA TV broadcasts. The Center's $\mathrm{AV}$ equipment makes it possible to gain access to foreign videos that cannot be played on American equipment. The LLC server stores digitized AV materials that cannot be distributed on the open web due to site licensing agreements or copyright issues. Besides these commercially available materials, the server also hosts interactive course packages designed by our faculty members. The use of these interactive materials requires special software, which students usually do not have access to on their own computers. Since the LLC is the only place on campus that hosts such a wealth of language learning materials, students frequently visit us and make use of all the materials we provide for language instruction.

The LLC lab is often booked for class demonstrations on accessing interactive language materials and on using different software programs. Even though many classrooms do have instructional computers and AV equipment, faculty members still use the LLC because students can have a first hand experience there. After viewing a demonstration, which is projected onto a big screen from the instructional computer mounted on the podium, students can immediately log into computers and begin practicing on their own. Class demonstration is not limited to language students from our department. Sometimes the music department also reserves the space for class demonstrations because our computer lab has the necessary audio software readily available. In addition, the LLC also aids faculty members in assessing students' language proficiency to accurately place them at different levels. The LLC is responsible for choosing the most suitable placement tests for different languages and administering the tests to freshmen in their orientation sessions. 


\section{An Engine for \\ Promoting Language Awareness}

Sixty-eight percent of Allegheny students come from Pennsylvania, while thirty-two percent of students are recruited from out of state. Allegheny College attracts many students from the surrounding regions. Many of our students are drawn to the college because they plan to go to medical school or law school after graduating from Allegheny College. Because of the regionalized geographical locations from which students are drawn, and their career aspirations, language learning may not be a priority for most of them when they first attend the college. Further still, at Allegheny College students are not required to take a foreign language to graduate. Hence, it is imperative for the department of Modern and Classical Languages to expose students to the importance and relevance of foreign language learning for their future careers. After all, a well-rounded person not only needs to possess some abilities to gather information from other languages in the age of globalization, but also should understand different world perspectives defined by different languages. Although the department has been successful in attracting a relatively large number of students, promoting language awareness becomes an ongoing and challenging process for the department because of the regional affiliation of the student body and their original career goals.

Besides striving for professional perfection in language instruction, the language department has been vigorously promoting cultural and language learning through a series of academic and cultural activities: language tables, language houses, cultural performances (such as French plays, Spanish performance, Chinese New Year Performance), invited lectures from alumni for possible career connections, lectures on cultural and translation topics, the promotion of Phi Sigma lota (International Foreign Language Honor Society), departmental picnics and so on. Through these activities, a community of language learning has been created at the College. To enable students to become totally immersed in other languages and cultures, the department also has study abroad programs in the following countries: Costa Rica, Mexico, France, Germany, and China. 
One crucial role of the LLC is to aid the language department in promoting language awareness and thus help attract students to enroll in language courses. In order to do so, it is important to let students realize that excellent language instruction is available on campus, to let the departmental academic and cultural activities reach an even wider audience, and to open study abroad opportunities to as many students as possible. With the advancement of technology, the LLC has become indispensable in this function. Since students today are technology-savvy and are used to learn visually, multimedia and the Internet play an important role in attracting their attention to different language programs on campus. With the help of multimedia software, it is possible for both current Allegheny students as well as for prospective applicants to visit a virtual language classroom, to get advice from fellow students, to learn about work opportunities after graduation, and to be immersed in cultural activities of different language programs at a time and place most convenient to them. At Allegheny College the websites of our different language programs, which include texts, hyperlinks, animated photos, and video clips, were created to familiarize students with language related activities and opportunities. These online materials can be used by on campus students as well as by prospective students. When prospective students visit our campus, they are shown video clips about our programs. We also put together a short documentary that the admissions office can use to direct the attention of prospective students towards language studies before they even get to campus.

For this purpose, we hired a student technologist to videotape classroom teaching, language tables, cultural performances, activities at language houses, and interviews with students. The technologist used a digital camcorder to record students' comments on their learning experience and happenings in classrooms, at language tables, in a language house, and at different cultural activities. We used Adobe Premiere to edit the footage. The edited material was divided and grouped under different themes, then authentic students' comments were illustrated by relevant pictures and clips. For example, when students commented on the fun of writing Chinese characters, the video cut to images of students writing characters with writing brushes. Cinematic techniques such as dissolve, close-up, looping, and cutting back and forth were used in the video clips for visual appeal, and subtitles were added to enhance clarity. In addition, traditional music was used as background music to enhance the audio effects. Then another student technologist converted these video clips to Flash format so that they would play well on the Internet. (One example is the homepage of the Chinese section at http://webpub.allegheny.edu/dept/language/chinese/index.html.) Finally, these video clips were put onto a DVD. 
The Future Direction of the LLC
Advanced software and hardware, AV equipment, and powerful computers as well as special technical skills are involved in the process of creating these effective multimedia and online materials, and thus the LLC is assuming a more and more prominent role in the midst of technical advancement that is not restricted to language teaching alone.

Thus far, we have seen the traditional roles of the LLC, and some of the new tasks are listed below. Besides continuously supporting the teaching of our traditional course offerings, the LLC is getting more and more involved in the support of the less commonly taught languages. Language learning software, the web, and telecommunication facilities help to connect outside evaluators with students.

As Burston (2005) points out, "the digital revolution has seen the emergence of web-based communication facilities such as campuswide course management systems and Internet audio-video and text messaging that can be readily integrated into language lab resources" (4). Because of this trend, the LLC is also becoming increasingly integrated into the campus-wide computing system. While the academic computing center concentrates on maintaining computers and the local network, the LLC concentrates on the selection and application of language related software to fully tap the potential for pedagogical application.

Over the last two decades, lab technology has evolved from analog to digital technology, and as it looks now will move more and more into the realm of web-based communication. As technology changes the way we teach language, new technologies will continue to place bigger burdens on an LLC, but at the same time make our centers more indispensable: we are responsible for the selection of the most suitable technology that caters to the needs a of faculty members and students. Our everyday work encompasses technology maintenance, the training of our faculty members, LLC assistants and students in the use of new technologies, and the dissemination of relevant pedagogical research and application into the most efficient and effective use of technology. Technological changes are unavoidable, and the best course of action for an LLC is to actively engage in technological changes and play an even greater role in language instruction and learning. 
NB: The author would like to thank Professor Peter Ensberg (Department of Modern and Classical Languages at Allegheny College) and Professor Louis Wagner (former LLC director at Allegheny College) for their constructive feedback.

\section{References}

Burston, J. (Ed.). 2005. IALLT Digital Language Lab Solutions: An Evaluation of Virtual Lab Programs. International Association for Language Learning Technology.

Gass, S. 2003. "Input and Interaction." In Doughty, C. \& Long, M. H. (Eds.) The Handbook of Second Language Acquisition. Malden, MA: Blackwell Publishing Ltd., 224-255.

Garrett, N. 1997. Language Media: Our Professional Future. IALLT Journal, 29 (3), 23-35. 